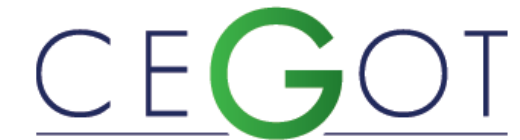

Centro de Estudos de Geografia e Ordenamento do Território
Geografia e Ordenamento do Território, Revista Eletrónica Centro de Estudos de Geografia e Ordenamento do Território http://cegot.org ISSN: 2182-1267

\title{
Qualidade dos recursos hídricos da bacia hidrográfica do córrego Formosinho, Bonito/MS
}

\author{
Quality of water resources of hydrographic basin of the Formosinho stream, Bonito/MS
}

Referência: Medeiros, Rafael; Berezuk, André; Pinto, André; Alves, Lorrane (2020). Qualidade dos recursos hídricos da bacia hidrográfica do Córrego Formosinho, Bonito/MS. Revista de Geografia e Ordenamento do Território (GOT), no 19 (Junho). Centro de Estudos de Geografia e Ordenamento do Território, p. 3-28, dx.doi.org/10.17127/got/2020.19.001

\section{RESUMO}

O objetivo do estudo é analisar a espacialização e a qualidade dos recursos hídricos da bacia hidrográfica do córrego Formosinho - BHCF. Para tanto, apoiou-se em propostas metodológicas de Christofoletti (1980) e a resolução 357/2005 do CONAMA, enfatizando-se a influência da geologia cárstica sobre a morfometria e da qualidade de suas águas superficiais da bacia. Os resultados apontaram que a rede de drenagem, apesar de possuir boa qualidade de suas águas, enquadradas na classe I do CONAMA, são escassas superficialmente, visto que muitos canais são efêmeros ou subterrâneos, gerando a necessidade em elaborar planos e manejos adequados para a dinâmica de um sistema cárstico, para garantir seu uso às atividades do turismo e da agropecuária.

Palavras-chave: Qualidade das águas superficiais; Morfometria da rede de drenagem; Sistema cárstico; Velocidade de fluxo. 


\section{ABSTRACT}

The objective of this study is to analyze the spatialization and quality of water resources of the Formosinho stream - BHCF watershed. For this, we are following Christofolletti's methodological proceedings (1980) and the rules of Decree 357/2005 by CONAMA (Brazilian Environment Council). That is good to know the karstic geology aspect when we are showing the local water quality and morphometry at superficial water of this river basin. Our results are emphasizing the drainage net good water quality (Class I by CONAMA), however the superficial water flux is scarce with many non-permanent channels (most of them at the underground level), generating the need to develop plans and appropriate management for the dynamics of a karst system to ensure their use for tourism and agricultural activities.

Palavras-chave: Surface water quality; Drainage network morphometry; Karstic systems; Flow velocity.

\section{Introdução}

O conhecimento sobre os recursos hídricos é essencial em quaisquer sistemas ambientais, porém devido às suas peculiaridades, os sistemas cársticos chamam mais a atenção e necessitam de maiores informações, por apresentar uma maior fragilidade, sobretudo no Brasil, em que, apesar de existirem estudos sobre esse sistema como Auler et al. (2001) que caracterizaram geologicamente a distribuição de 14 áreas carbonáticas no Brasil, ainda carece de maiores avanços em suas avaliações. A análise integrada das características desses sistemas hídricos, por meio das suas propriedades hidrogeológicas, morfométricas e qualidade de suas águas pode fornecer a compreensão de seu "modus operandi", com informações indispensáveis para seu uso e manejo múltiplo sustentável.

Fatos estes, que são identificados na Bacia Hidrográfica do Córrego Formosinho (doravante, designada por BHCF), área de estudo deste artigo, localizada no município de Bonito/Mato Grosso do Sul. A área possui um sistema cárstico que retrata uma diversidade notável de unidades morfoestruturais e recursos hídricos, sendo estes, os principais modeladores desta paisagem cárstica.

Diante da utilização da bacia hidrográfica como um sistema a ser analisado, a Lei no 9.433/1997 trouxe um avanço na gestão das águas no Brasil, considerando a bacia como unidade territorial para a implementação da Política Nacional de Recursos Hídricos (Brasil, 1997). No âmbito do município de Bonito, questões relacionadas aos mananciais foram colocadas em discussão, mais precisamente referente aos rios cênicos, que são influenciados pela dinâmica dos sistemas cársticos. A Lei no 1.871/1998 discorre justamente 
sobre essas questões, indicando uma forma de conservação da natureza, proteção do meio ambiente e defesa das margens nas áreas contíguas aos rios cênicos de Bonito e Jardim (município localizado a sudoeste de Bonito), (Mato Grosso do Sul, 1998).

A Lei no $1.871 / 1998$, juntamente com a Lei no $2.223 / 2001$, se baseiam na importância da proteção dos rios cênicos e seus afluentes, responsabilizando proprietários e arrendatários de imóveis rurais e urbanos pela poluição e contaminação dos mananciais. Os proprietários que possuem rios cênicos em seus domínios são responsáveis pela conservação perante os órgãos de fiscalização do Sistema Estadual de Gerenciamento de Recursos Hídricos (Mato Grosso do Sul, 2001). Outro fator que deve ser evidenciado é a proibição do uso direto das águas dos rios cênicos, preservando sua qualidade e quantidade.

Com o intuito de analisar os recursos hídricos é necessário trabalhar com indicadores, objetivando compreender a dinâmica dos mananciais frente à possíveis usos predatórios, além de sua importância na constatação de prováveis desequilíbrios e impactos ambientais, sendo a morfometria um importante método para a análise destes recursos.

Por se tratar de uma região cárstica, a presença de mananciais na superfície é restrita, existindo uma grande percolação das águas pelas fendas e fissuras das rochas, existindo uma preocupante fragilidade, sobretudo diante de um possível uso inadequado que acarreta desequilíbrios no sistema (Van Beyden e Van Beyden, 2001). Já Parise (2012) menciona que não interpretar as características cársticas e suas fragilidades (baixa resiliência; solos férteis, porém frágeis; e a alta dissoluçao das rochas que pode acarretar em abatimentos do terreno) resulta em uma má gestão de seus recursos hídricos.

Diante de tais apontamentos, Waele et al. (2011) destacam cinco questões a serem tratadas em estudos sobre o carste: predominância de drenagens subterrâneas; caráter oculto da rede de condutos subterrâneos, tornando-se difícil seu mapeamento e obtêm uma resposta imprevisível frente às múltiplas alterações antrópicas; c) baixa resiliência; d) alta solubilidade; e) ante seu comportamento peculiar, exige um manejo adequado.

Dessa forma, as reações químicas definem a evolução do carste e, segundo Carvalho Júnior et al (2008) estão associadas ao processo de dissolução do calcário, tendo controle sobre a circulação das águas na superfície. Por meio disso, a morfologia e hidrologia são específicas, tanto na superfície como no subterrâneo, resultante da circulação hídrica. 
Ao trabalhar com recursos hídricos, observa-se a necessidade de entender sua espacializaçao e quantidade de mananciais existentes, e ainda como estes são influenciados pelas atividades existentes na bacia hidrográfica. Uma das melhores formas de se compreender tais problemas ambientais é por meio da análise da qualidade das águas superficiais, que trazem consigo uma interpretação de que as águas são consideradas um elo entre todos os componentes físicos e antrópicos de uma bacia hidrográfica. Sua variação vai identificar possíveis contaminações, sendo utilizadas como indicadores ambientais por meio de seus parâmetros físicos e químicos.

É preciso contextualizar sobre os parâmetros físico-químicos em sistemas cársticos, pois suas características hidrológicas e geoquímicas são modificadas pelas rochas carbonatadas que condicionam o fluxo aos dutos, fraturas e matrizes das rochas, além da influência hidrogeológica notável. Essa relação é o que determina as características das águas superficiais da BHCF, e diante das análises dos parâmetros selecionados como indicadores, foi importante levar em consideração tais particularidades, constatando-as por meio de diversas obras como Silva et al. (2014); Lelis et al. (2015); Mantovani et al. (2016); Brugnolli et al. (2020); Brugnolli (2020).

Os parâmetros físicos e químicos estão, portanto, relacionados a uma série de fatores que compõem essa bacia hidrográfica, sobretudo seu substrato rochoso, ou seja, sua influência sobre as águas é notável, principalmente devido à carstificação das rochas carbonatadas, onde os armazenamentos das águas subterrâneas influenciam às águas superficiais, deixando-a com uma característica alcalina com altos índices de sólidos totais dissolvidos e condutividade elétrica, prejudicando seu enquadramento. Por sua vez, a turbidez dessas águas ganha destaque, pois apresenta poucos sedimentos em suspensão, devido à floculação e decantação do carbonato de cálcio das rochas carbonatadas no leito fluvial.

Diante destes parâmetros, a Resolução 357 do CONAMA (2005) dispõe sobre a classificação dos recursos hídricos e diretrizes ambientais para o seu enquadramento, juntamente aos parâmetros para a definição das classes de enquadramento, que é basicamente um conjunto de condições e padrões de qualidade de água necessários ao atendimento dos usos preponderantes, atuais ou futuros (CONAMA, 2005). Esta resolução traz especificações para determinar a qualidade de mananciais hídricos, considerando que a água integra as preocupações do desenvolvimento sustentável, baseado nos princípios da função ecológica 
da propriedade, da prevenção, da precaução, do poluidor-pagador, do usuário-pagador e da integração, bem como no reconhecimento de valor intrínseco à natureza (CONAMA, 2005).

Tais conceitos e formas de compreensão dos recursos hídricos da BHCF, nortearam as justificativas para essa pesquisa, tal qual o avanço das monoculturas em suas terras férteis, porém frágeis, podendo ocasionar alterações nos parâmetros físico-químicos das águas superficiais ante ao possível arraste de sedimentos, provocando impactos significativos, inclusive nas tufas calcárias, que são um dos principais atrativos turísticos de Bonito, pois as mesmas ocasionam quedas d'água, corredeiras, dentre outras feições cársticas.

Além disso, os recursos hídricos da BHCF possuem papel imprescindível nos setores sociais, econômicos e ambientais de Bonito, na medida em que são as principais fontes de rendas na cidade. O aspecto social surge no que diz respeito à geração de empregos diretos e indiretos relacionados às atratividades turísticas; o setor econômico também voltado ao turismo, visto que tanto o comércio como o setor hoteleiro vislumbram um ambiente em que favoreça o aumento das atividades turisticas. Este setor ambiental, onde se insere os recursos hídricos, estão vinculados diretamente à qualidade das águas, seja por sua translucidez e outros parâmetros que afetam diretamente o turismo da região.

Neste percurso, a presente pesquisa objetiva analisar a espacialização da rede de drenagem (morfometria da rede de drenagem) e compreender e enquadrar a qualidade das águas superficiais da BHCF na resolução do CONAMA (2005), utilizando-se parâmetros físicoquímicos para aferir o método de correlação de Pearson, importante método básico para identificar possíveis correlações entre os próprios parâmetros.

\section{2. Área de Estudo}

A BHCF possui grande relevância para o município de Bonito-MS, seja por suas águas translúcidas, com elevada beleza cênica, e por se tratar de um importante afluente do rio Formoso (manancial mais importante de Bonito e que possui grande atratividade turística). A área da BHCF abrange parte do Parque Nacional da Serra da Bodoquena e o Monumento Natural Estadual da Gruta do Lago Azul e diante da relevancia deste manancial hídrico é que justificamos a seleção desta área para a elaboração deste artigo. 
A BHCF apresenta uma dimensão territorial de $414,31 \mathrm{~km}^{2}$, localizada a oeste do município de Bonito, tendo seu rio principal uma extensão de $30,54 \mathrm{~km}$, desaguando no médio curso do rio Formoso. Ao longo de seu percurso, o mesmo apresenta afluentes importantes que auxiliam na dinâmica das águas do córrego Formosinho, como o Córrego Taquaral e Anhumas, ambos com suas nascentes localizadas na Serra da Bodoquena (Figura 1).

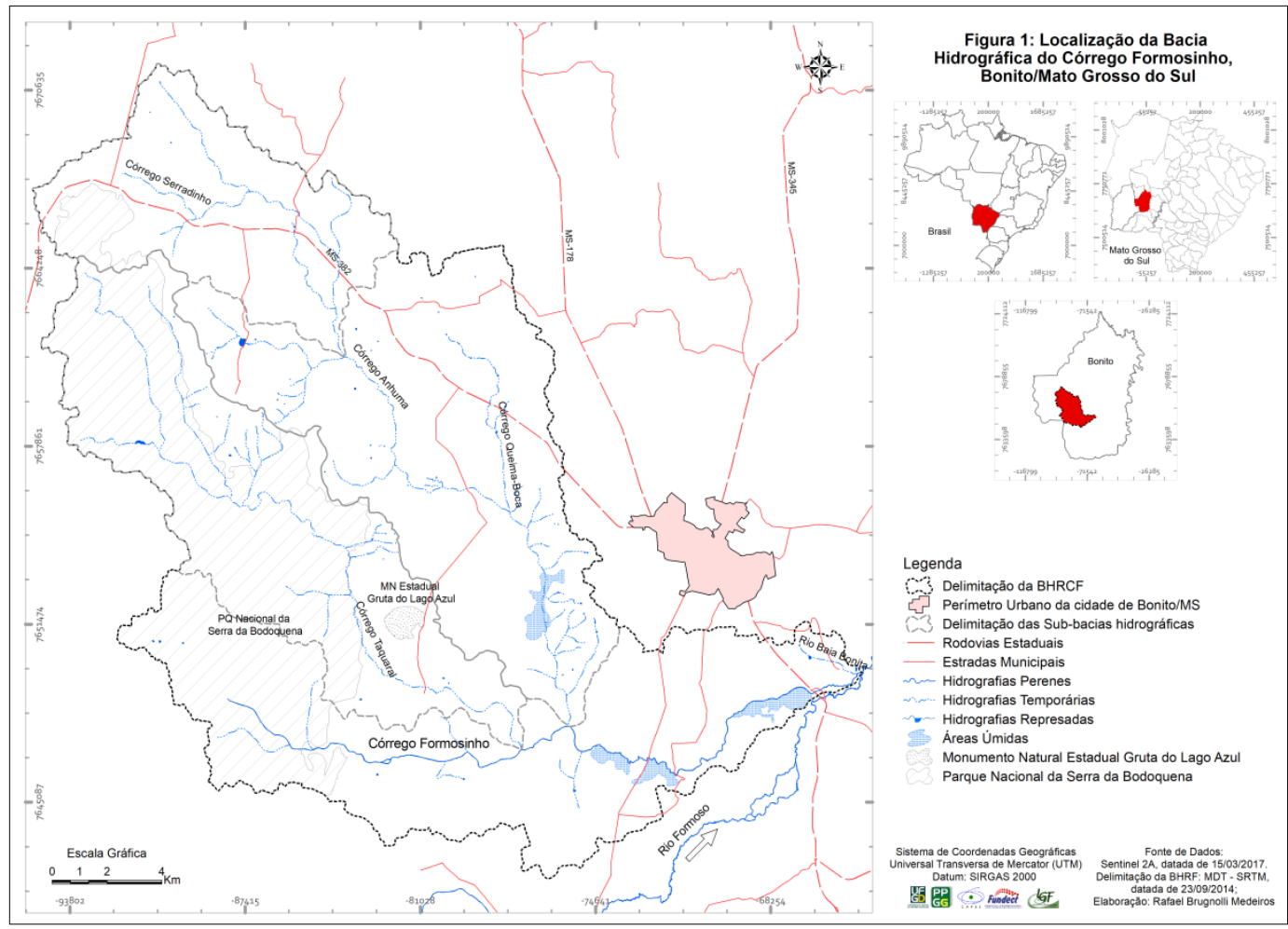

Figura 1 - Localização da BHCF, Bonito/MS com suas principais sub-bacias hidrográficas Fonte: Elaboração própria com dados do MDT- SRTM

Diante de tal localização, a BHCF está situada em terrenos carbonatados do Grupo Corumbá que modelaram um relevo cárstico formado por áreas serranas da Serra da Bodoquena até regiões aplainadas onde há um predomínio de solos férteis, tanto o chernossolo rêndzico órtico como o latossolo vermelho eutrófico e nitossolo vermelho eutrófico.

Com o intuito de caracterizar o aspecto climático da área em estudo foi utilizado o trabalho do Zavatini (1992), referência para estudos no Mato Grosso do Sul e que embasara a compreensão da dinâmica dos elementos climáticos da BHCF. Logo, o autor propôs uma classificação climática do estado e diante de tal proposta, a BHCF ficou inserida na zona climática controlada por massas tropicais e polares, com um clima regional predominante da atuação da massa polar atlântica e participação efetiva da massa tropical continental. 
Por fim, a BHCF está inserida no contexto Planalto da Bodoquena, sendo esta uma das feições climáticas individualizadas propostas pelo autor, com "índices anuais entre 1200 e $1400 \mathrm{~mm}$, chuvas de primavera ligeiramente superiores às de verão e período outonoinverno com valores ao redor de 300 mm" (Zavatini, 1992, p.84).

\section{Materiais e Métodos}

A análise dos recursos hídricos da BHCF consiste em identificar a morfometria da drenagem e a qualidade das águas superficiais. A análise morfométrica segue a clássica proposta de Christofoletti (1980). Índices foram levados em consideração, como: 1) área de drenagem; 2) perímetro; 3) ordem dos canais; 4) relação de bifurcação; 5) comprimento médio dos segmentos fluviais, 6) relação entre o comprimento médio dos canais de cada ordem; 7) relação entre o índice médio do comprimento médio dos canais e o índice de bifurcação; 8) extensão do percurso superficial; 9) forma da bacia; 10) índice de circularidade, 11) densidade hidrográfica; 12) densidade de drenagem; e 13) coeficiente de manutenção.

Com relação à velocidade de fluxo das águas e sua qualidade, as mesmas foram analisadas ao longo de 6 pontos de coleta nos principais mananciais da BHCF, ou seja, nos córregos Taquaral, Anhuma, Serradinho e no próprio córrego Formosinho (Figura 2). Foram realizadas diversas saídas de campo, utilizando dados do inverno de 2017.

A velocidade de fluxo ocorre mediante a utilização, em campo, do equipamento Global Water FP101 - FP201 e com o objetivo de coletar os dados referentes aos parâmetros físicos e químicos selecionados para avaliar a qualidade das águas, o equipamento utilizado foi o Horiba U-50 Series Multiparameter water Quality Unit's (Figura 3).

Os indicadores utilizados na análise das águas da BHCF foi o Oxigênio Dissolvido - OD, Potencial Hidrogeniônico - pH, Condutividade Elétrica - CE, Temperatura do da Água, Turbidez, Potencial Redox, Sólidos Totais Dissolvidos - TDS e Salinidade (Tabela 1). Juntamente a tais parâmetros, realizou-se a medição da velocidade de fluxo das águas, variável que auxilia na oxigenação das águas. 


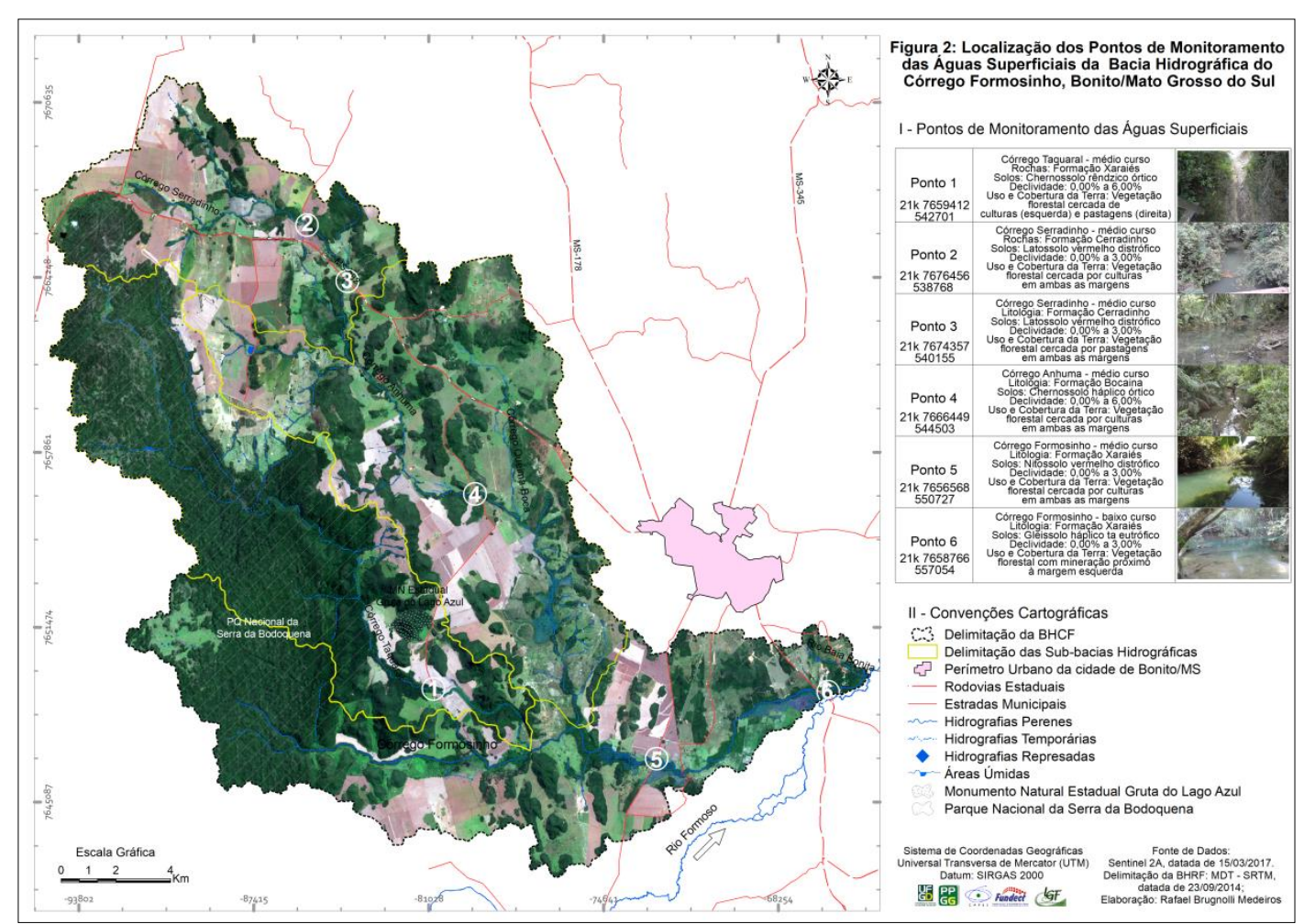

Figura 2 - Localização dos Pontos de Monitoramento das Águas Superficiais da BHCF, Bonito/MS Fonte: Elaboração própria com dados Sentinel 2A, datada de 15/03/2017

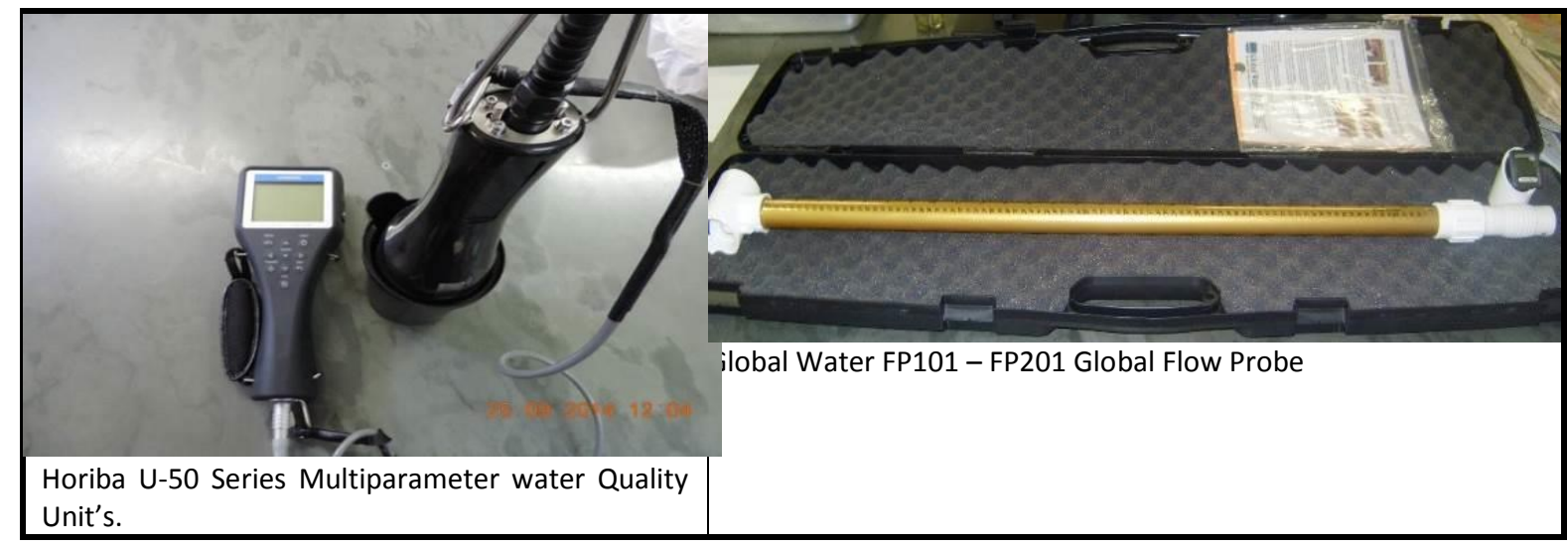

Figura 3 - Equipamentos utilizados na Mensuração da qualidade das águas superficiais da BHCF. Fonte: Elaboração própria

Após sua medição, foi realizada a interpretação dos dados coletados e efetuado o enquadramento dos recursos hídricos, segundo a resolução 357/2005 do CONAMA, que determina os limites dos parâmetros e suas principais preconizações (Tabela 2). É válido destacar que o parâmetro de condutividade elétrica não é abordado pela Resolução, mas por ser um indicador que aponta informações importantes foi decidido incorporá-lo na avaliação, tendo como referência nos limites deste indicador os trabalhos de Pinto et al. (2009), Lelis et al. (2015), Brugnolli (2016) e Brugnolli et al. (2019a). 
Tabela 1 - Parâmetros e autores que trabalham com os parâmetros físicos e químicos utilizados.

\begin{tabular}{|c|c|c|}
\hline Parâmetros & Autores & Definiçãa \\
\hline OD & $\begin{array}{l}\text { Araújo et al. } \\
\text { (2004) }\end{array}$ & $\begin{array}{l}\text { Gás solúvel em água, com concentrações variadas, podendo ser utilizado como } \\
\text { indicador de qualidade das águas, pois a proliferação bacteriológica depende de suas } \\
\text { concentrações, passível de realização no campo. }\end{array}$ \\
\hline $\mathrm{pH}$ & $\begin{array}{l}\text { Libânio } \\
\text { (2005) }\end{array}$ & $\begin{array}{l}\text { Consiste na concentração dos íons } \mathrm{H}+\text { nas águas e representa a intensidade das } \\
\text { condições ácidas ou alcalinas do ambiente aquático. }\end{array}$ \\
\hline CE & $\begin{array}{l}\text { Libânio } \\
\text { (2005) }\end{array}$ & $\begin{array}{l}\text { Capacidade da água natural de transmitir a corrente elétrica em função da presença } \\
\text { de substâncias dissolvidas que se dissociam em ânions e cátions, sendo, por } \\
\text { consequência, diretamente proporcional à concentração iônica. }\end{array}$ \\
\hline $\begin{array}{l}\text { Temp. } \\
\text { Água }\end{array}$ & $\begin{array}{l}\text { Libânio } \\
\text { (2005) }\end{array}$ & $\begin{array}{l}\text { A temperatura da água indica a magnitude da energia cinética do movimento } \\
\text { aleatório das moléculas e sintetiza o fenômeno de transferência de calor à massa } \\
\text { líquida. }\end{array}$ \\
\hline Velocidade & $\begin{array}{l}\text { Brugnolli } \\
(2016)\end{array}$ & $\begin{array}{l}\text { A velocidade de fluxo traz ao ambiente aquático, um turbilhonamento das águas, } \\
\text { fazendo com que ocorra uma oxigenação e sua consecutiva melhora em seu } \\
\text { enquadramento. }\end{array}$ \\
\hline Turbidez & $\begin{array}{l}\text { Libânio } \\
\text { (2005) }\end{array}$ & $\begin{array}{l}\text { Se constitui em uma inferência da concentração de partículas suspensas presentes na } \\
\text { massa líquida, e apresentam significados semelhantes em termos de qualidade de } \\
\text { água. }\end{array}$ \\
\hline ORP & $\begin{array}{l}\text { Ivo e Kubica } \\
\text { (2009) }\end{array}$ & $\begin{array}{l}\text { Potencial de redução das soluções aquosas, podem variar de acordo com a perda e } \\
\text { recebimento de elétrons de uma solução. }\end{array}$ \\
\hline TDS & $\begin{array}{l}\text { AquaAmbiente } \\
\text { (2004) }\end{array}$ & $\begin{array}{l}\text { Sais dissolvidos na água (cloretos, bicarbonatos e outros), parâmetro este, que deve } \\
\text { fundamentalmente ao solo que a água atravessa, traduzindo a quantidade de } \\
\text { materiais que a água dissolveu. }\end{array}$ \\
\hline Salinidade & $\begin{array}{l}\text { CONAMA } \\
(2005)\end{array}$ & $\begin{array}{l}\text { A Salinidade (\%) indica as concentrações de sódio na água, que podem ser naturais ou } \\
\text { derivadas a fezes animais ou esgotos, sobretudo domésticos. Naturais, as águas doces } \\
\text { oscilam de } 0,0 \text { a } 0,005 \% \text {. }\end{array}$ \\
\hline
\end{tabular}

Fonte: Elaboração própria.

Tabela 2 - Parâmetros para enquadramento das águas e seus usos preponderantes

\begin{tabular}{|c|c|c|c|c|c|c|c|c|}
\hline \multirow[b]{2}{*}{ Classes } & \multicolumn{8}{|c|}{ Enquadramento das Águas Superficiais } \\
\hline & OD & pH & $\begin{array}{c}\text { Turbi- } \\
\text { dez }\end{array}$ & CE & TDS & ORP & $\begin{array}{l}\text { Salini- } \\
\text { dade }\end{array}$ & $\begin{array}{c}\text { Principais Preconizações para a utilização das } \\
\text { Águas Superficiais }\end{array}$ \\
\hline Especial & $\begin{array}{l}>10,0 \\
\mathrm{mg} / \mathrm{L}\end{array}$ & $\begin{array}{c}6,0 \mathrm{a} \\
9,0\end{array}$ & $\begin{array}{l}0 \text { a } 20 \\
\text { NTU }\end{array}$ & $\begin{array}{l}0 \text { a } 50 \\
\mathrm{uS} / \mathrm{cm}\end{array}$ & $\begin{array}{c}0 \text { a } 200 \\
\mathrm{mg} / \mathrm{L}\end{array}$ & $\begin{array}{c}0 \text { a } 300 \\
m V\end{array}$ & 0,00 & $\begin{array}{l}\text { Consumo humano com desinfecção; Preservação do } \\
\text { equilíbrio das comunidades aquáticas. }\end{array}$ \\
\hline I & $\begin{array}{c}10 \text { a } 6 \\
\mathrm{mg} / \mathrm{L}\end{array}$ & $\begin{array}{c}6,0 \mathrm{a} \\
9,0\end{array}$ & $\begin{array}{c}20 \text { a } 40 \\
\text { NTU }\end{array}$ & $\begin{array}{c}50 \text { a } 75 \\
u S / c m\end{array}$ & $\begin{array}{l}200 \mathrm{a} \\
300 \\
\mathrm{mg} / \mathrm{L}\end{array}$ & $\begin{array}{c}300 \mathrm{a} \\
400 \mathrm{mV}\end{array}$ & 0,00 & $\begin{array}{l}\text { Consumo humano, após tratamento simplificado; } \\
\text { Proteção das comunidades aquáticas; Recreação de } \\
\text { contato primário (natação e mergulho); Irrigação de } \\
\text { hortaliças que são consumidas cruas e de frutas que } \\
\text { se desenvolvam rentes ao solo e que sejam } \\
\text { ingeridas sem remoção de películas. }\end{array}$ \\
\hline II & $\begin{array}{l}6 \text { a } 5 \\
\mathrm{mg} / \mathrm{L}\end{array}$ & $\begin{array}{c}6,0 \mathrm{a} \\
9,0\end{array}$ & $\begin{array}{c}40 \text { a } 70 \\
\text { NTU }\end{array}$ & $\begin{array}{l}75 \text { até } \\
100 \\
\text { uS } / \mathrm{cm}\end{array}$ & $\begin{array}{c}300 \mathrm{a} \\
400 \\
\mathrm{mg} / \mathrm{L}\end{array}$ & $\begin{array}{c}400 \mathrm{a} \\
500 \mathrm{mV}\end{array}$ & 0,00 & $\begin{array}{l}\text { Consumo humano após tratamento convencional, à } \\
\text { proteção das comunidades aquáticas, à recreação } \\
\text { de contato primário, tais como natação e mergulho, } \\
\text { à irrigação de hortaliças, plantas frutíferas e de } \\
\text { parques, jardins, campos de esporte e lazer, com os } \\
\text { quais o público possa vir a ter contato direto. }\end{array}$ \\
\hline III & $\begin{array}{l}5 \text { a } 4 \\
\mathrm{mg} / \mathrm{L}\end{array}$ & $\begin{array}{c}6,0 \mathrm{a} \\
9,0\end{array}$ & $\begin{array}{l}70 \text { a } \\
100 \\
\text { NTU }\end{array}$ & $\begin{array}{c}100 \text { a } 150 \\
\text { uS } / \mathrm{cm}\end{array}$ & $\begin{array}{l}400 \mathrm{a} \\
500 \\
\mathrm{mg} / \mathrm{L}\end{array}$ & $\begin{array}{c}500 \mathrm{a} \\
600 \mathrm{mV}\end{array}$ & 0,00 & $\begin{array}{l}\text { Consumo humano após tratamento convencional ou } \\
\text { avançado, à irrigação de culturas arbóreas e } \\
\text { forrageiras, pesca amadora, recreação de contato } \\
\text { secundário e dessedentação de animais. }\end{array}$ \\
\hline IV & $\begin{array}{c}<4 \\
\mathrm{mg} / \mathrm{L}\end{array}$ & $\begin{array}{c}6,0 \mathrm{a} \\
9,0\end{array}$ & $\begin{array}{c}>100 \\
\text { NTU }\end{array}$ & $\begin{array}{l}+150 \\
\mathrm{uS} / \mathrm{cm}\end{array}$ & $\begin{array}{l}>500 \\
\mathrm{mg} / \mathrm{L}\end{array}$ & $>600 \mathrm{mV}$ & $>0,00$ & Navegação e à harmonia paisagística \\
\hline
\end{tabular}

Fonte: Adaptação da resolução CONAMA 357/2005. 
Para a realização da correlação entre os próprios parâmetros foi realizado o método de correlação de Pearson, disponibilizado no software Microsoft Office Excel. Todas essas informações, somadas aos dados disponibilizados pela Companhia de Pesquisa de Recursos Minerais - CPRM a respeito das unidades morfoestratigráficas e seus elementos estruturais, trazem consigo uma análise conjunta dos recursos hídricos locais, possibilitando a compreensão da influência do substrato rochoso sobre os mesmos. Diante das informações disponibilizadas pela CPRM e a fim de promover maior detalhamento das formações geológicas existentes na BHCF foram realizadas saídas de campo, alcançando o detalhamento desta pesquisa (1:150.000).

\section{Resultados}

Um importante tópico a ser analisado é a estreita relação dos recursos hídricos com o seu substrato rochoso (Figura 4). A distribuição da rede de drenagem e a qualidade das águas da BHCF tem sua estrutura influenciada pelo relevo cárstico, onde as nascentes dos principais mananciais estão situadas na serra da Bodoquena.

De tal forma, identificou-se, a partir da análise morfométrica, pouca densidade superficial de drenagem, devido a mesma apresentar características criptorreicas, com turbidez reduzida, elevado teor de sólidos totais dissolvidos e condutividade elétrica pela dissolução da calcita, dolomita e magnésio das rochas calcárias. Destacou-se ainda, um pH alcalino, devido à alta concentração de bicarbonato de cálcio dissolvido nas águas, desse modo, estas são consideradas algumas das características que podem ser traduzidas como passíveis de influência das rochas carbonatadas em um sistema cárstico

Dos seis pontos de coleta, convêm destacar os altos teores de oxigênio dissolvido, com exceção do ponto número 1, que traduzem uma água dotada de boa qualidade. Portanto, seu ambiente cárstico, com rochas carbonatadas (calcário e mármores calcíticos e dolomíticos), por vezes, com relevo muito declivoso e solos frágeis, alteram os parâmetros físicos e químicos das águas, sobretudo pela influência hidrogeológica. 


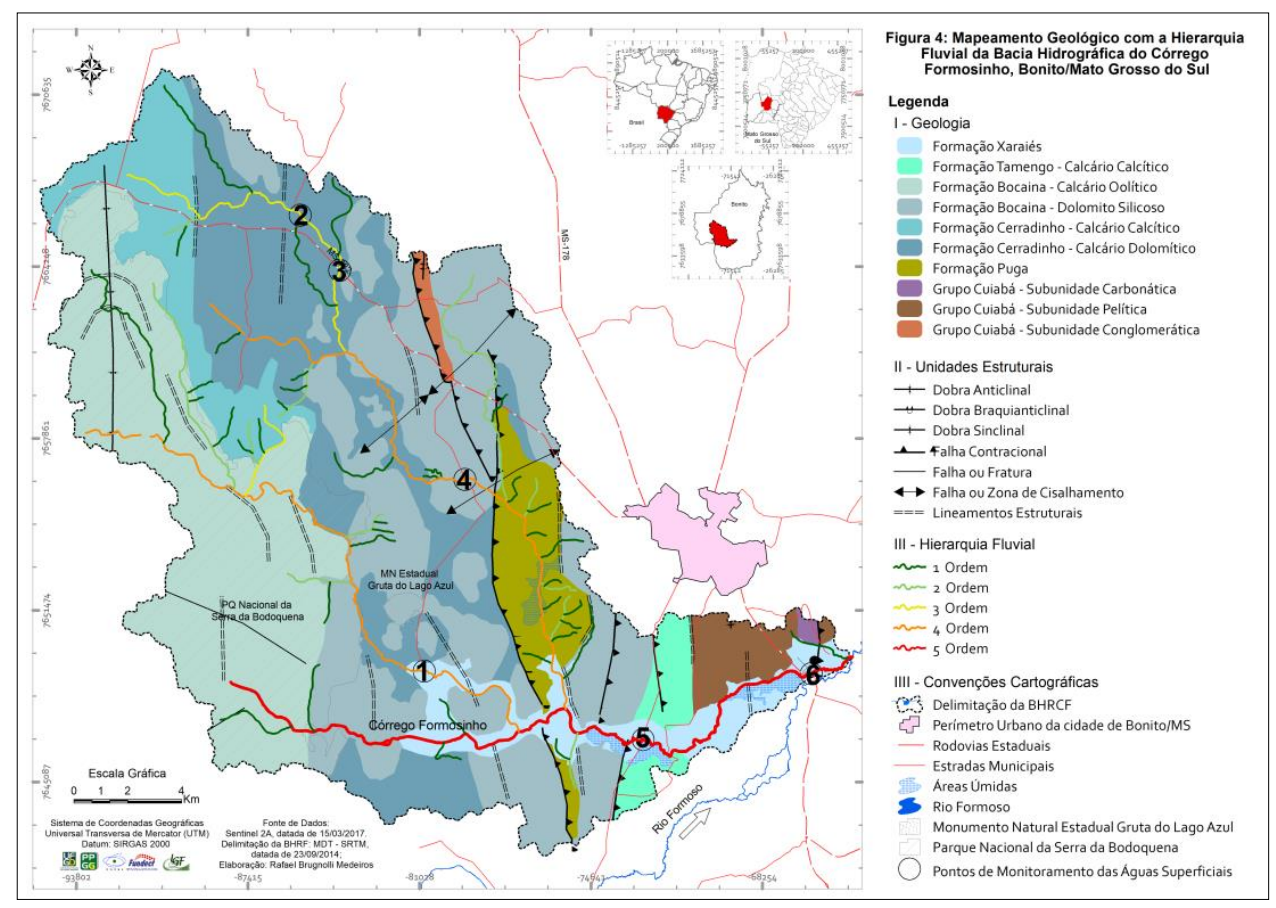

Figura 4 - Mapeamento Geológico com a Hierarquia Fluvial da BHCF, Bonito/MS Fonte: Elaboração própria com dados do CPRM (2006)

\subsection{Análise morfométrica da rede de drenagem da BHCF}

A BHCF possui um total de 55 canais de drenagem, sendo estes 39 de primeira ordem (71\%), segundo o método de Horton. A densidade de drenagem varia, portanto, de 0,09 a 0,16 segmentos fluviais por quilômetro quadrado (Tabela 3).

Mesmo dotada de uma densidade de drenagem muito baixa, típica de áreas cársticas que influenciam uma significativa infiltração hídrica, a BHCF apresenta sua maior quantidade de drenagens em topografia mais acidentada da bacia, isto é, nas áreas serranas (Serra da Bodoquena). A BHCF apresenta uma densidade de drenagem de $0,46 \mathrm{~km} / \mathrm{km}^{2}$, já o coeficiente de manutenção possui valores de $2.185 \mathrm{~m}^{2} / \mathrm{m}$ para a BHCF.

Também relacionado à topografia da região da BHCF, o comprimento médio dos canais de primeira ordem da BHCF correspondeu a $1,48 \mathrm{~km}^{2}$, sobretudo devido a presença de solos mais argilosos provenientes da intemperização do calcário e da dolomita. Outro dado se refere a extensão do percurso superficial da BHCF com extensão de 2,19 km, que reforça a presença de solos argilosos e em concordância com a topografia mais íngreme no alto curso da BHCF que resulta em uma maior energia cinética das águas, oferecendo condições para um maior percurso superficial. 
Tabela 3 - Morfometria da rede de drenagem da BHCF, Bonito/MS

\begin{tabular}{|c|c|c|c|c|c|c|c|c|}
\hline \multirow{3}{*}{\multicolumn{5}{|c|}{ Fator de Análise }} & \multicolumn{4}{|c|}{ Bacias Hidrográficas } \\
\hline & & & & & \multirow[b]{3}{*}{$\begin{array}{l}\text { Córrego } \\
\text { Taquaral }\end{array}$} & \multirow{2}{*}{\multicolumn{2}{|c|}{$\begin{array}{l}\text { Córrego Formosinho } \\
\text { Córrego Anhuma }\end{array}$}} & \multirow{3}{*}{$\begin{array}{c}\text { Total } \\
\text { Córrego } \\
\text { Formosinho }\end{array}$} \\
\hline & & & & & & & & \\
\hline $\begin{array}{c}\text { Análise da } \\
\text { Rede } \\
\text { Drenagem }\end{array}$ & \multicolumn{2}{|c|}{ Características } & Unidade & $\begin{array}{l}\text { Canais } \\
\text { Fluviais }\end{array}$ & & $\begin{array}{c}\text { Córrego } \\
\text { Serradinho }\end{array}$ & \begin{tabular}{|c|} 
Total \\
Córrego \\
Anhuma
\end{tabular} & \\
\hline \multirow{4}{*}{$\begin{array}{c}\text { Características } \\
\text { da Bacia } \\
\text { Hidrográfica }\end{array}$} & \multicolumn{2}{|c|}{ Área de drenagem $(\mathrm{A})$} & $\mathrm{km}^{2}$ & -- & 106,06 & 65,59 & 189,14 & 414,31 \\
\hline & \multicolumn{2}{|c|}{ Perímetro $(\mathrm{P})$} & $\mathrm{km}$ & -- & 72,51 & 46,61 & 90,23 & 132,01 \\
\hline & \multicolumn{2}{|c|}{$\begin{array}{c}\text { Características } \\
\text { Cársticas }\end{array}$} & $\%$ & -- & 100,00 & 100,00 & 88,26 & 92,45 \\
\hline & \multicolumn{2}{|c|}{$\begin{array}{c}\text { Características } \\
\text { Terrígenas }\end{array}$} & $\%$ & -- & 0,00 & 0,00 & 11,74 & 7,55 \\
\hline \multirow{7}{*}{$\begin{array}{l}\text { Hierarquia } \\
\text { Fluvial }\end{array}$} & \multirow{7}{*}{\multicolumn{2}{|c|}{ Ordem dos Canais }} & \multirow{7}{*}{$\begin{array}{c}\text { Horton - } \\
\text { Número de } \\
\text { Seguimentos }\end{array}$} & 1 Ordem & 10 & 4 & 23 & 39 \\
\hline & & & & 2 Ordem & 4 & 1 & 6 & 11 \\
\hline & & & & 3 Ordem & 1 & 1 & 1 & 2 \\
\hline & & & & 4 Ordem & 1 & -- & 1 & 2 \\
\hline & & & & 5 Ordem & -- & -- & -- & 1 \\
\hline & & & & 6 Ordem & -- & -- & -- & -- \\
\hline & & & & Total & 16 & 6 & 31 & 55 \\
\hline \multirow{22}{*}{ Análise Linear } & \multirow{5}{*}{\multicolumn{2}{|c|}{$\begin{array}{l}\text { Relação de } \\
\text { Bifurcação }\end{array}$}} & \multirow{5}{*}{-- } & $1 / 2$ Ordem & 2,50 & 4,00 & 3,83 & 3,55 \\
\hline & & & & $2 / 3$ Ordem & 4,00 & 1,00 & 6,00 & 5,50 \\
\hline & & & & $3 / 4$ Ordem & 1,00 & -- & 1,00 & 1,00 \\
\hline & & & & 4/5 Ordem & -- & -- & -- & 2,00 \\
\hline & & & & 5/6 Ordem & -- & -- & -- & -- \\
\hline & \multirow{6}{*}{\multicolumn{2}{|c|}{$\begin{array}{l}\text { Comprimento médio } \\
\text { dos segmentos fluviais }\end{array}$}} & \multirow{6}{*}{$\mathrm{km}$} & 1 Ordem & 1,86 & 3,14 & 1,52 & 1,48 \\
\hline & & & & 2 Ordem & 3,71 & 1,53 & 2,99 & 3,13 \\
\hline & & & & 3 Ordem & 4,38 & 14,46 & 14,46 & 7,89 \\
\hline & & & & 4 Ordem & 25,71 & -- & 25,29 & 25,50 \\
\hline & & & & 5 Ordem & -- & -- & -- & 30,54 \\
\hline & & & & 6 Ordem & -- & -- & -- & -- \\
\hline & \multirow{5}{*}{\multicolumn{2}{|c|}{$\begin{array}{c}\text { Relação entre o } \\
\text { comprimento médio } \\
\text { dos canais de cada } \\
\text { ordem }\end{array}$}} & \multirow{5}{*}{--} & 2/1 Ordem & 1,99 & 0,49 & 1,96 & 2,11 \\
\hline & & & & $3 / 2$ Ordem & 1,18 & 9,48 & 4,84 & 2,52 \\
\hline & & & & 4/3 Ordem & 5,88 & -- & 1,75 & 3,23 \\
\hline & & & & 5/4 Ordem & -- & -- & -- & 1,20 \\
\hline & & & & $6 / 5$ Ordem & -- & -- & -- & -- \\
\hline & \multirow{5}{*}{\multicolumn{2}{|c|}{$\begin{array}{c}\text { Relação entre o índice } \\
\text { médio do } \\
\text { comprimento médio } \\
\text { dos canais e o índice } \\
\text { de bifurcação } \\
\end{array}$}} & \multirow{5}{*}{--} & $1 / 2$ Ordem & 1,25 & 8,23 & 1,95 & 1,68 \\
\hline & & & & $2 / 3$ Ordem & 3,39 & 0,11 & 1,24 & 2,18 \\
\hline & & & & 3/4 Ordem & 0,17 & -- & 0,57 & 0,31 \\
\hline & & & & 4/5 Ordem & -- & -- & -- & 1,67 \\
\hline & & & & 5/6 Ordem & -- & -- & -- & -- \\
\hline & $\begin{array}{r}\text { Extensão c } \\
\text { supe }\end{array}$ & $\begin{array}{l}\text { o percurso } \\
\text { ficial }\end{array}$ & $\mathrm{km}$ & -- & 1,67 & 2,30 & 2,04 & 2,19 \\
\hline \multirow{4}{*}{ Análise Areal } & $\begin{array}{l}\text { Forma da } \\
\text { Bacia }\end{array}$ & \begin{tabular}{|c|} 
Índice de \\
Circulari- \\
dade
\end{tabular} & -- & & 0,25 & 0,37 & 0,29 & 0,30 \\
\hline & $\begin{array}{l}\text { Dens } \\
\text { Hidro }\end{array}$ & $\begin{array}{l}\text { dade } \\
\text { ráfica }\end{array}$ & $\begin{array}{c}\mathrm{n}^{\circ} \mathrm{de} \\
\text { segmentos } \\
\text { fluviais } / \mathrm{km}^{2}\end{array}$ & -- & 0,15 & 0,09 & 0,16 & 0,13 \\
\hline & $\begin{array}{r}\text { Densid } \\
\text { Dren }\end{array}$ & $\begin{array}{l}\text { ade de } \\
\text { agem }\end{array}$ & $\mathrm{km} / \mathrm{km}^{2}$ & -- & 0,60 & 0,44 & 0,49 & 0,46 \\
\hline & $\begin{array}{r}\text { Coefici } \\
\text { Manu }\end{array}$ & $\begin{array}{l}\text { nte de } \\
\text { enção }\end{array}$ & $\mathrm{m}^{2} / \mathrm{m}$ & -- & $1.668,25$ & $2.297,51$ & $2.042,30$ & $2.185,46$ \\
\hline
\end{tabular}


A BHCF possui canais de primeira ordem curtos e runoffs que refletem um coeficiente de manutenção de $414 \mathrm{~km}^{2}$. O perímetro de $132 \mathrm{~km}$ da BHCF remete a um perímetro altamente irregular, cujo índice de circularidade baixo comprova $(0,30)$. Um índice circular baixo como este também comprova a alta influência topográfica da BHCF, sendo esta uma bacia com influência ao escoamento hídrico e menores tendências de inundação.

Em se tratando das sub-bacias da BHCF, o córrego Taquaral apresenta toda sua dimensão territorial em ambiente cárstico, logo, toda a área manifesta baixa densidade de drenagem, apesar de possuir o maior valor, ou seja, de 0,60 km/ $\mathrm{km}^{2}$. Seu manancial é de 4a ordem, devido a quantidade de afluentes existentes na parte da serra da Bodoquena, com isso, possui uma densidade hidrográfica de 0,15 segmentos fluviais por $\mathrm{km}^{2}$. Ainda que tenha uma ampla abundância de sumidouros e ressurgências nesta sub-bacia, grande parte de seus mananciais (tributários do córrego Taquaral) são encontrados na serra da Bodoquena.

Apesar da área retratar uma baixa densidade de drenagem, representa o menor coeficiente de manutenção $\left(1.668,25 \mathrm{~m}^{2} / \mathrm{m}\right)$ e o menor percurso superficial de todas as sub-bacias $(1,67$ km). O córrego é intermitente, percorrendo terrenos muitos íngremes, desde sua nascente a vales encaixados na serra da Bodoquena, até sua foz, no córrego Formosinho.

Já o córrego Serradinho, que é afluente do córrego Anhuma, foi qualificado como 3a ordem, com sua dimensão territorial influenciada pelo sistema cársticos, havendo uma densidade de drenagem e densidade hidrográfica de $0,44 \mathrm{~km} / \mathrm{km}^{2}$ e de 0,09 cursos por $\mathrm{km}^{2}$, respectivamente. Este córrego não possui extensos tributários, assim, sua quantidade de bifurcações é baixa.

O córrego Anhuma apresentou 0,16 cursos por $\mathrm{km}^{2}$ de densidade hidrográfica e uma densidade de drenagem de $0,49 \mathrm{~km} / \mathrm{km}^{2}$. Há de se destacar uma grande concentração de mananciais de pequena extensão nas menores áreas dotadas de rochas terrígenas $(11,74 \%$ dos $189,14 \mathrm{~km}^{2}$, ou seja, $6,21 \mathrm{~km}^{2}$ ).

O córrego Formosinho, com seus afluentes citados anteriormente e demais tributários têm uma densidade de drenagem de 0,46 km/ $\mathrm{km}^{2}$, com 0,13 cursos por $\mathrm{km}^{2}$ de densidade hidrográfica. De forma geral, percebe-se que os recursos hídricos ficaram dispostos, em maior quantidade, nas áreas preservadas da serra da Bodoquena, isto é, no alto curso da BHCF. Já em áreas do médio e baixo curso da BHCF a quantidade de mananciais foi menor, 
devido ao aumento das áreas aplainadas e maior ocorrência de áreas úmidas nas planícies aluviais.

Esses dados morfométricos auxiliam na identificação das características dos recursos hídricos e sua disponibilização ao longo das bacias hidrográficas, sobretudo no que diz respeito a influência que as características cársticas exercem sobre os recursos hídricos. No mais, é importante ressaltar os parâmetros físicos e químicos das águas superficiais, destacando-se a importância da análise da qualidade destes mananciais, proporcionando assim, além da identificação de sua distribuição, a sua qualidade vigente.

\subsection{Qualidade das águas superficiais da BHCF}

Ao longo de 6 pontos de monitoramento realizou-se análises de alguns parâmetros físicos e químicos das águas superficiais juntamente com a correlação de Pearson, que traduz, de forma simples e rápida, a relação entre os próprios parâmetros (Tabela 4).

Tabela 4 - Resultado das coletas e enquadramento das águas superficiais da BHCF, Bonito/MS, em 2017 e matriz de correlação entre os parâmetros

\begin{tabular}{|c|c|c|c|c|c|c|c|c|c|c|c|}
\hline Pontos & $\begin{array}{c}\text { OD } \\
(\mathrm{mg} / \mathrm{L})\end{array}$ & $\begin{array}{c}\text { CE } \\
(\mu S / \mathrm{cm})\end{array}$ & $\mathrm{pH}$ & $\begin{array}{c}\text { Turbi- } \\
\text { dez } \\
\text { (NTU) }\end{array}$ & $\begin{array}{l}\text { Vel. } \\
(\mathrm{m} / \mathrm{s})\end{array}$ & $\begin{array}{c}\text { Temp. Ar } \\
\left({ }^{\circ} \mathrm{C}\right)\end{array}$ & $\begin{array}{c}\text { Temp. } \\
\text { Água } \\
\left({ }^{\circ} \mathrm{C}\right)\end{array}$ & $\begin{array}{l}\text { ORP } \\
(\mathrm{mV})\end{array}$ & $\begin{array}{c}\text { TDS } \\
\text { (mg/L) }\end{array}$ & $\begin{array}{l}\text { Salin. } \\
(\%)\end{array}$ & $\begin{array}{l}\text { Enqua- } \\
\text { dramento }\end{array}$ \\
\hline 1 & 3,45 & 185,00 & 7,78 & 3,18 & 0,10 & 25,16 & 24,65 & 202,00 & 121,00 & 0,01 & II \\
\hline 2 & 8,41 & 183,00 & 7,94 & 6,24 & 0,57 & 25,62 & 26,96 & 186,00 & 118,00 & 0,01 & I \\
\hline 3 & 7,35 & 143,00 & 8,18 & 1,81 & 15,83 & 27,08 & 23,98 & 175,00 & 193,00 & 0,01 & I \\
\hline 4 & 7,45 & 204,00 & 7,74 & 1,24 & 0,08 & 25,17 & 23,62 & 204,00 & 123,00 & 0,01 & 1 \\
\hline 5 & 6,81 & 213,00 & 7,61 & 0,65 & 5,83 & 25,62 & 24,56 & 171,00 & 139,00 & 0,01 & 1 \\
\hline 6 & 8,68 & 185,00 & 7,71 & 1,24 & 15,28 & 33,51 & 27,38 & 182,00 & 120,00 & 0,01 & 1 \\
\hline Média & 7,03 & 185,50 & 7,83 & 2,39 & 6,27 & 27,03 & 25,19 & 186,67 & 135,67 & 0,01 & 1 \\
\hline $\begin{array}{l}\text { Classe } \\
\text { Classe } \\
\text { Classe } \\
\text { Classe } \\
\text { Classe }\end{array}$ & Especial & & & & & & & & & & \\
\hline
\end{tabular}

Matriz de Correlação de Pearson

\begin{tabular}{|c|c|c|c|c|c|c|c|c|c|c|}
\hline OD & OD & & & & & & & & & \\
\hline CE & $-0,06$ & CE & & & & & & & & \\
\hline pH & 0,13 & $-0,93$ & $\mathrm{pH}$ & & & & & & & \\
\hline Turbidez & 0,02 & $-0,22$ & 0,38 & Turbi. & & & & & & \\
\hline Veloc. & 0,41 & $-0,57$ & 0,33 & $-0,46$ & Veloc. & & & & & \\
\hline Temp.Ar & 0,49 & $-0,19$ & $-0,10$ & $-0,29$ & 0,74 & Temp.Ar & & & & \\
\hline Temp. Água & 0,47 & 0,00 & $-0,11$ & 0,46 & 0,18 & 0,64 & Temp. & & & \\
\hline ORP & $-0,44$ & 0,21 & $-0,16$ & 0,25 & $-0,66$ & $-0,29$ & $-0,16$ & ORP & & \\
\hline TDS & 0,05 & $-0,72$ & 0,71 & $-0,29$ & 0,62 & $-0,06$ & $-0,47$ & $-0,56$ & TDS & \\
\hline Salin. & $-0,23$ & 0,39 & 0,11 & 0,09 & $-0,20$ & $-0,43$ & $-0,23$ & $-0,12$ & 0,32 & Salin. \\
\hline
\end{tabular}

Fonte: Elaboração própria 
O córrego Taquaral, ponto 1 de monitoramento das águas, merece destaque na BHCF, pois seu alto curso ainda se mantém preservado, situado no Parque Nacional da Serra da Bodoquena, todavia, $O \mathrm{OD}$ do ponto em questão foi o que apresentou o dado mais preocupando, se comprado com os outros pontos de análise, isto é, $3,45 \mathrm{mg} / \mathrm{L}$.

Tal resultado, é justificado devido à reduzida velocidade e quantidade de fluxo de suas águas $(0,10 \mathrm{~m} / \mathrm{s})$, além da grande quantidade de folhas e galhos existentes em seu leito fluvial, observado em campo, havendo um depósito constante de matéria orgânica ao longo de seu canal, que impacta diretamente nos níveis de oxigênio dissolvido.

Mesmo com a tendência à formação de um sistema redutor, o pH apresentou 7,78. No que se refere a turbidez, ORP e TDS constatou-se que seus valores não se apresentaram críticos, fazendo com o que este ponto fosse enquadrado na classe II, mas como este apresentou os piores resultados da BHCF sugeriu-se promover algumas medidas mitigadoras locais, como a redução de áreas de culturas próximas, que estão cada vez mais adentrando nas áreas de tálus das matas ciliares e morros residuais próximos (que ainda se mostram preservados).

De acordo com os moradores da propriedade rural que margeia o ponto 1 , o córrego Taquaral apresentava grande vazão de água, mas na saída de campo de Dezembro de 2016 e Março de 2017, o mesmo não apresentava água em seu leito, constatando um fluxo apenas no Inverno de 2017, mas com pouca velocidade e reduzido volume (Figura 5).

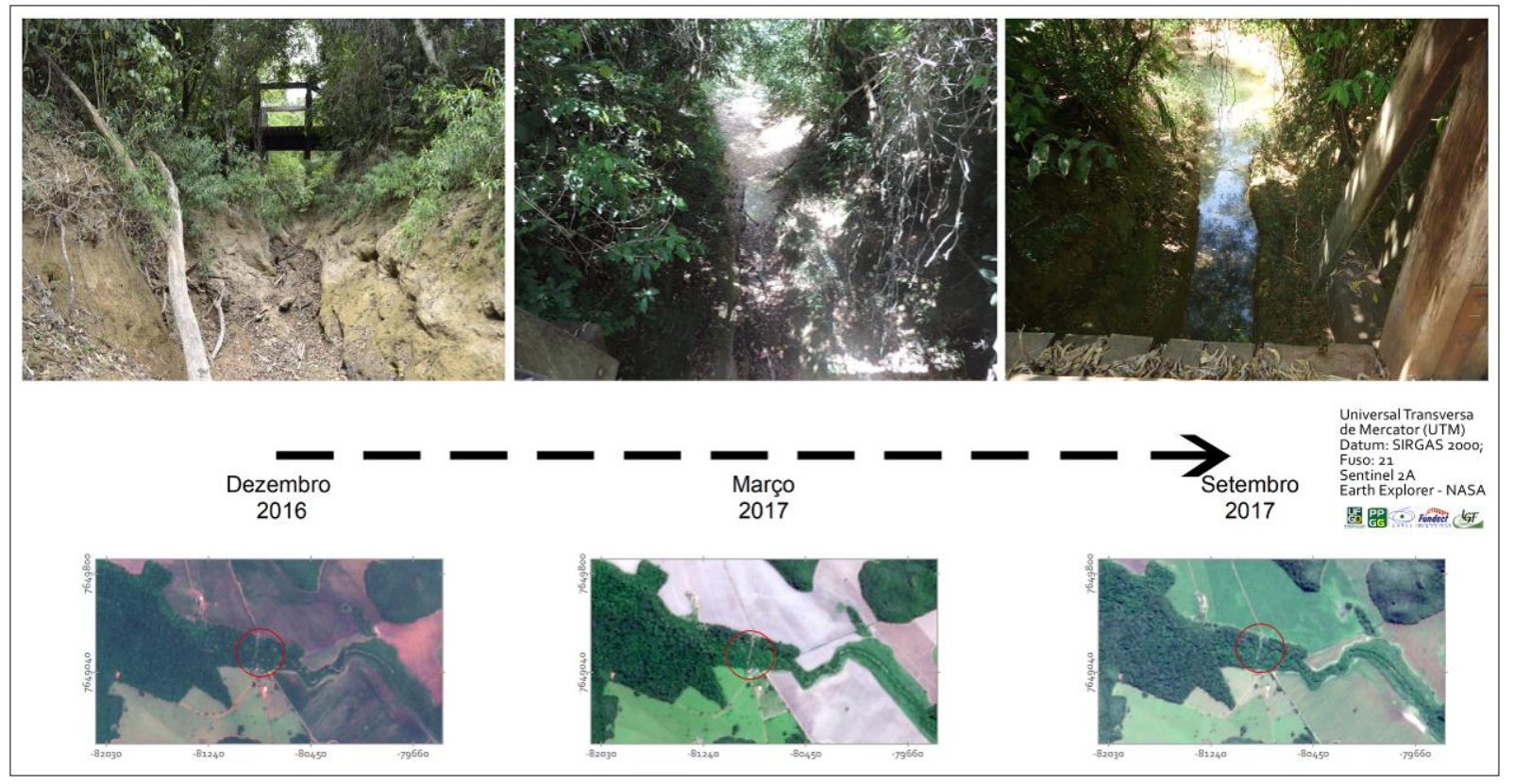

Figura 5 - Evolução do volume das águas superficiais do córrego Taquaral Fonte: Elaboração própria 
No córrego Serradinho foram dois pontos de monitoramento da qualidade das águas (pontos 2 e 3), distanciados por aproximadamente 2,8 km, que também causaram preocupação devido ao volume hídrico reduzido. É possível constatar, pela imagem de satélite e com as idas à campo, um provável desvio de captação das águas do córrego Serradinho para o abastecimento de um açude, pertencente a uma propriedade rural da área. Foi constatado, também, represamentos das águas ao longo dos $2,8 \mathrm{~km}$ de percurso entre o ponto 2 e ponto 3 , e este represamento provoca a redução do OD devido ao baixo turbilhonamento das águas, isto é, $8,41 \mathrm{mg} / \mathrm{L}$, no ponto 2 , para $7,35 \mathrm{mg} / \mathrm{L}$, no ponto 3 . É válido enfatizar preocupações frente a esta ação antrópica, sobretudo, no que toca à redução na vazão das águas superficiais locais, como pode ser observado na Figura 6.

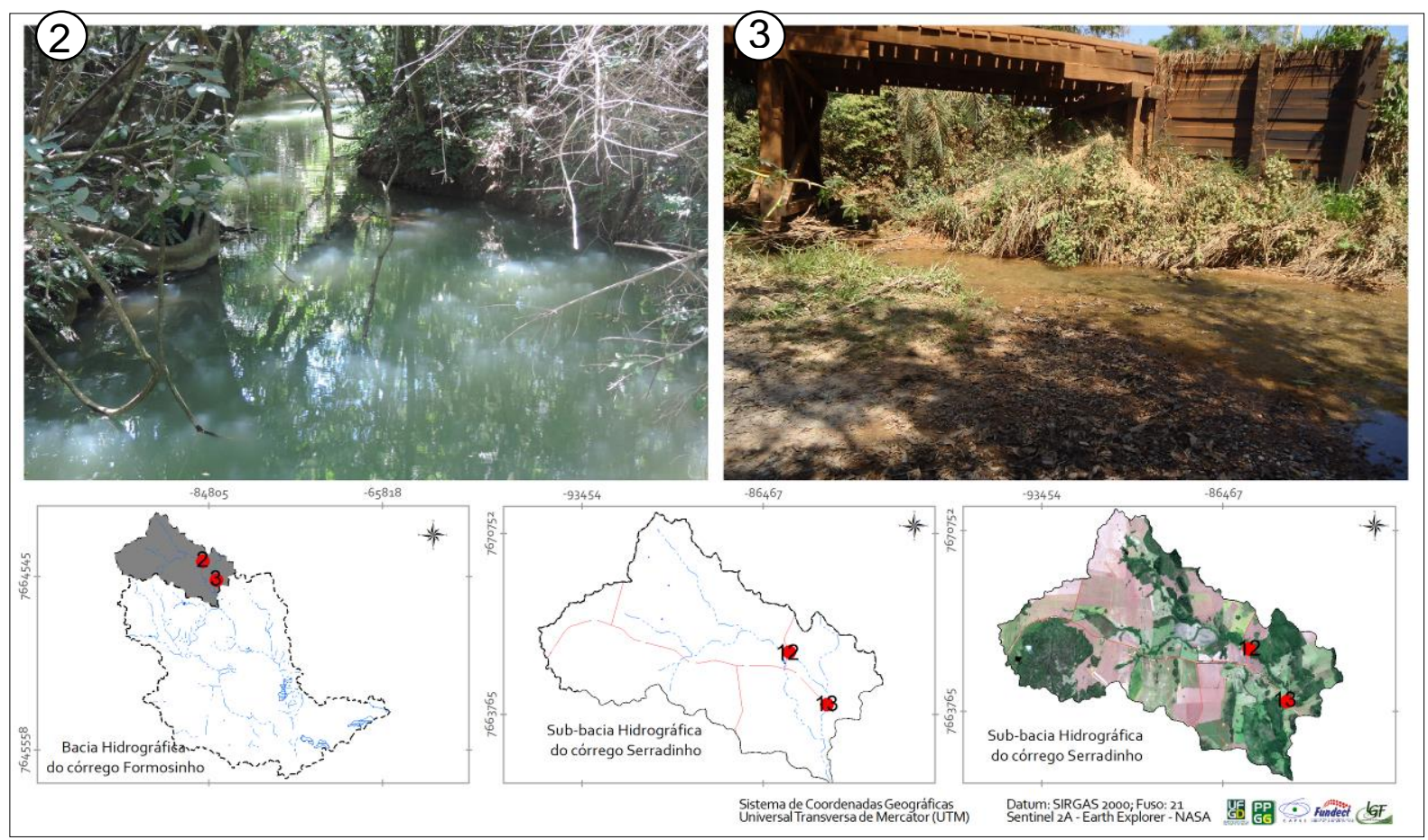

Figura 6 - Córrego Serradinho perde o volume de suas águas em pontos com poucos metros de distância

Fonte: Elaboração própria

Um fator positivo, referente ao ponto 3, que colabora com a diminuição dos impactos no volume hídrico é o aumento da velocidade do fluxo, que permite a manutenção dos níveis de $\mathrm{OD}$, mas logo após o ponto 3 encontrou-se, novamente, mais um represamento das águas superficiais, refletindo na redução abrupta desta velocidade, acarretando na diminuição do $O D$ e aumentando as tensões ecológicas neste ambiente aquoso, 
influenciando nas águas superficiais à jusante, isto é, o córrego Anhuma, como pode ser observado na Figura 7.

O ponto 4 apresentou uma velocidade de fluxo muito reduzida, mas o OD se mostrou elevado, com 7,45 mg/L. Durante a coleta dos dados in situ, foi observado a retirada das águas superficiais do córrego Anhuma por caminhões pipa para a construção da rodovia MS382 que estava sendo pavimentada e a retirada constante e em grande quantidade de água do leito fluvial é um fato considerado impactante e preocupante para o ambiente aquático. Portanto, é notória a alta vulnerabilidade ambiental destas áreas, onde intervenções pontuais podem causar impactos negativos ao longo do sistema da bacia hidrográfica.

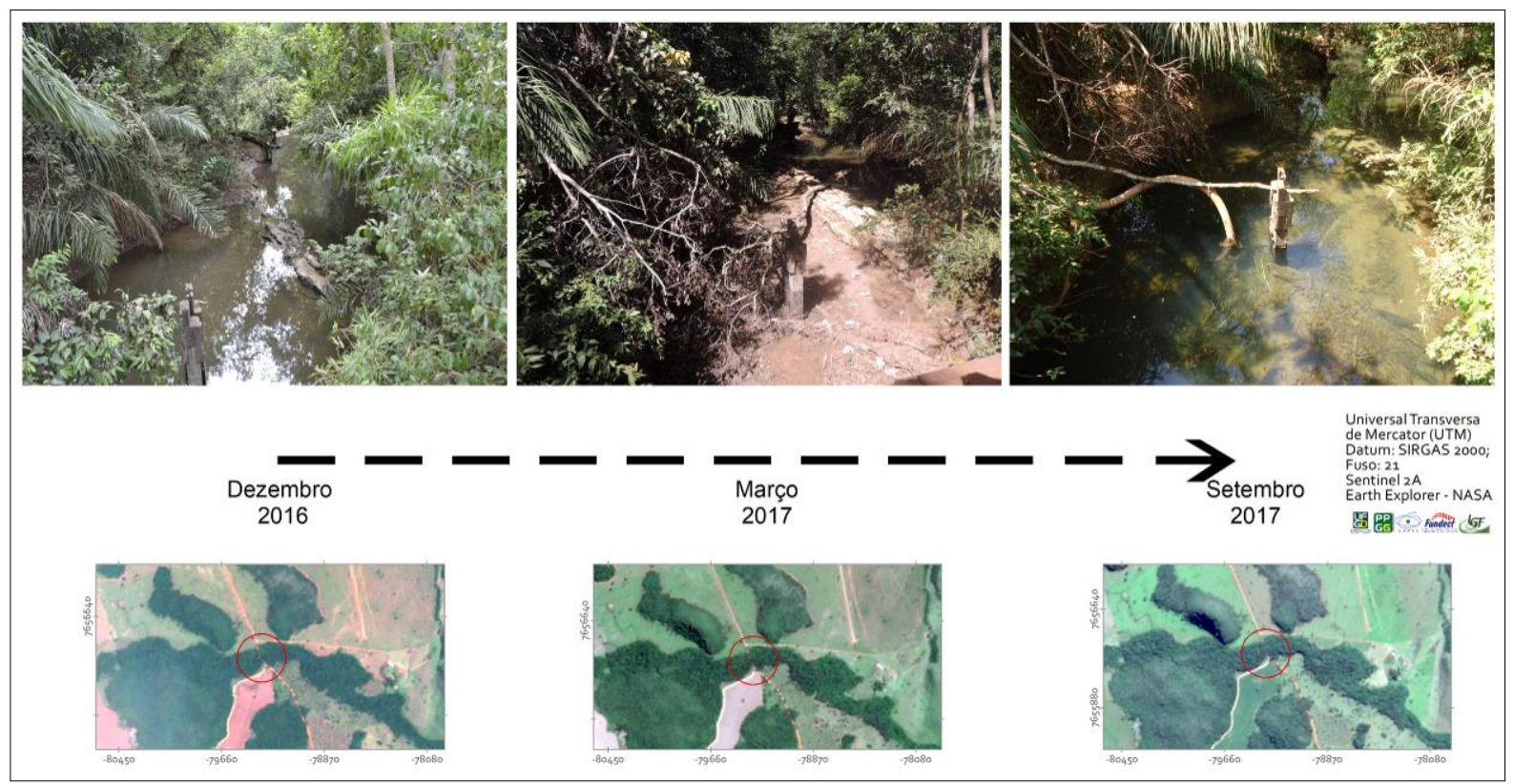

Figura 7 - Córrego Anhuma sofreu uma perda total no vazão das águas durante o verão de 2017 retomando suas águas no inverno de 2017

Fonte: Elaboração própria

Esse ponto 4 apresenta as mesmas características da maioria dos pontos analisados, com uma condutividade elétrica elevada $(204,00 \mu \mathrm{S} / \mathrm{cm})$ devido a influencia do substrato rochoso, isto é, calcita, dolomita e magnésio dissolvidos na água pelas rochas calcárias de seu leito fluvial.

Um fato importante é que, mesmo com baixa velocidade de fluxo, seu OD permaneceu elevado, sobretudo por algumas quedas d'água situadas a poucos metros a montante, causando um turbilhonamento e uma reoxigenação das águas, porém, logo após essas 
quedas foi observado um novo represamento das águas (natural), reduzindo-se, novamente, a velocidade de fluxo.

Diante do volume e qualidade dos mananciais Taquaral (ponto 1), Serradinho (pontos 2 e 3) e Anhuma (ponto 4), foi observada uma grande necessidade de conservação, não apenas para com as suas sub-bacias hidrográficas, mas com a BHCF como um todo.

O córrego Formosinho apresenta, por sua vez, características perenes, com uma maior vazão de água, por outro lado, alguns de seus tributários são temporários e isso inferiu em seu regime. Frente a estas observações há uma preocupação com a qualidade, quantidade e dinâmica do córrego Formosinho, sendo este um dos principais tributários do Formoso, manancial fundamental nas atividades econômicas do município de Bonito.

O ponto 5 (córrego Formosinho) apresentou uma redução na oxigenação das águas $(6,81$ $\mathrm{mg} / \mathrm{L})$, sobretudo, pela significativa quantidade de matéria orgânica e vegetação aquática existentes (matéria orgânica que não impactou de maneira significativa na qualidade do corpo hídrico local graças a uma velocidade de fluxo de 5,83 m/s).

Mesmo com uma redução da oxigenação, suas águas ainda permaneceram em níveis aceitáveis segundo o CONAMA, enquadrada como classe I. Por outro lado, a condutividade se mostrou mais elevada, sobretudo pelo leito fluvial percorrer sobre ambientes cársticos, com tufas calcárias e travertinos, da Formaçao Xaraiés. Segundo Dias (2000), essa influência das rochas ocorre pelas grandes concentrações de magnésio, alumínio e cálcio das rochas carbonatadas, sobretudo do grupo Corumbá e Formação Xaraiés.

A turbidez encontra-se reduzida neste ponto, ocasionando a tradicional beleza cênica das águas da bacia, expressando uma coloração azulada da água do córrego Formosinho. Há perceptível influência das rochas carbonatadas no alto curso, e das formações Bocaina, Cerradinho e Xaraiés no médio curso, apresentando translucidez das águas, (pontos 5 e 6), Figura 8.

Neste último ponto de análise (ponto 6), o OD do córrego Formosinho apresenta melhorias na medida em que se aproxima de sua foz, pois há um ligeiro aumento da velocidade de fluxo, acarretando um turbilhonamento das águas e maior oxigenação, elevando o OD para $8,68 \mathrm{mg} / \mathrm{L}$. Com isso, permanece com boa qualidade das águas (classe I de enquadramento), não oferecendo grande empecilho para seu uso. Um fator a ser destacado foi a alta 
condutividade elétrica, o pH e turbidez, que também se elevaram devido ao aumento dos sólidos totais das águas, por meio do aumento da velocidade de fluxo que solaparam as margens do manancial que, segundo Fritzsons et al. (2009) destacam, são fatores que elevam do $\mathrm{pH}$, deixando-o ainda mais alcalino e alterando seu equilíbrio. Alguns fatores expõem a área a uma maior fragilidade, tendo como consequencia os solapamentos, como a ausência da mata ciliar e atividade de mineração, representado no ponto 6 .

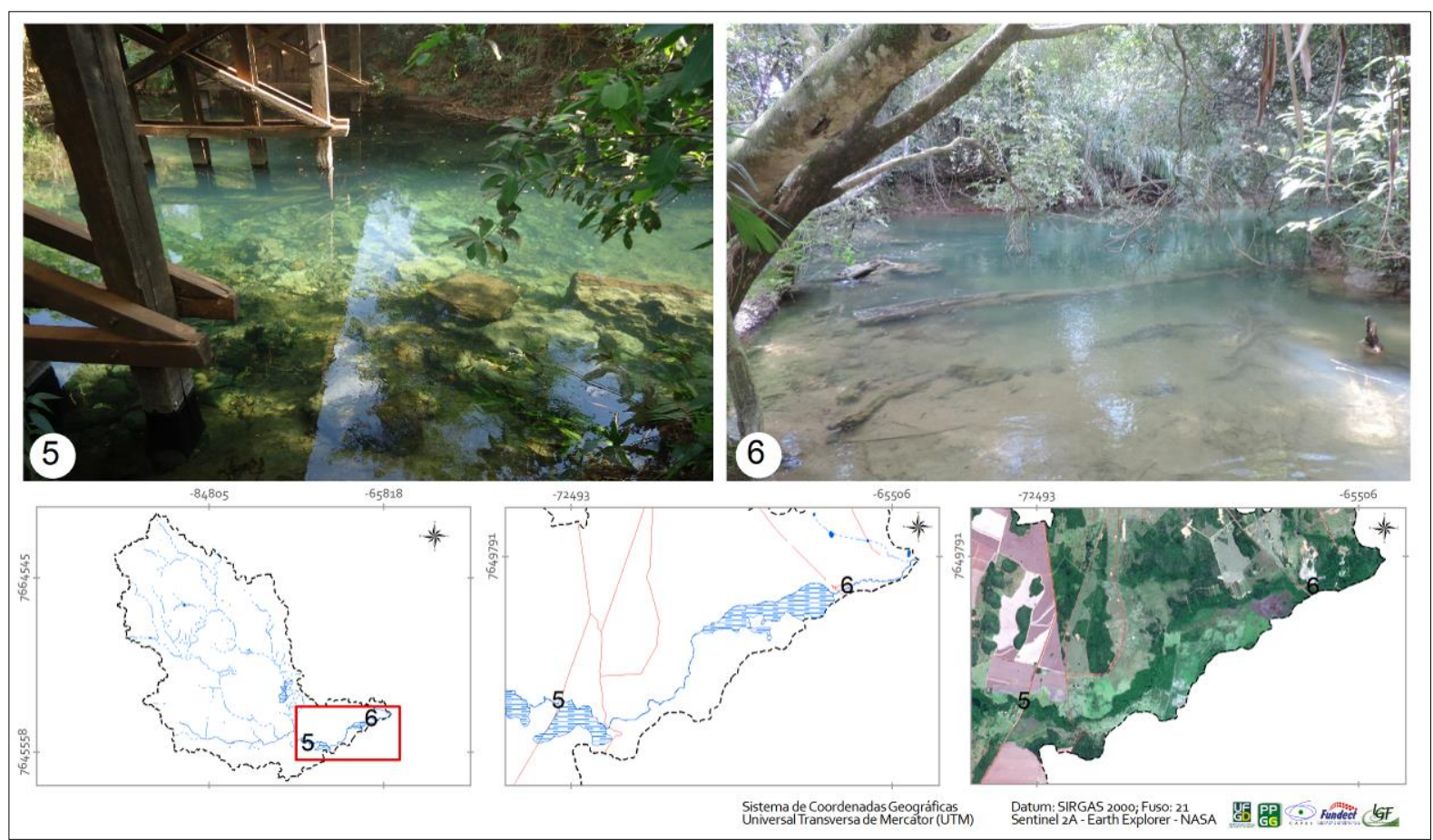

Figura 8 - Turbidez reduzida do córrego Formosinho, ocasionando uma beleza cênica ao manancial Fonte: Elaboração própria

A presença, à montante, de uma mineração de calcário do ponto de monitoramento 6 , segundo Silva (2007), causa impacto poluidor devido a grande quantidade de lama que pode possuir compostos químicos, tais como ferro, calcário, areia e argila. A área da mineração não adentra as áreas de preservação permanente, contudo, seu monitoramento deve ser continuo, sobretudo em épocas chuvosas, onde o escoamento superficial é elevado.

Por meio dessas análises, há uma influência de alguns parâmetros sobre outros, sendo necessário, conforme apontado na Tabela 2, uma correlação destes, expondo uma tendência caso algum parâmetro seja alterado nessa atual análise da qualidade das águas da BHCF. Observou-se que o OD foi influenciado, diretamente, pela velocidade de fluxo das 
águas, por meio de seu turbilhonamento, com a presença de quedas d'água e corredeiras que provocaram sua oxigenação. O OD é influenciado, também, pela temperatura das águas, pois a solubilidade dos gases se eleva com a redução da temperatura, logo, as águas que se apresentaramm com temperaturas mais amenas tendem a reter mais oxigênio.

Por outro lado, o pH nessas áreas permaneceu dentro do limite aceitável de boa qualidade, sobretudo pelas poucas variações existentes, que segundo Brugnolli et al. (2019a) pode ser explicado pela grande capacidade de "efeito tampão" destas águas devido ao alto valor de carbonatos e bicarbonatos dissolvidos na água, apresentando alterações pouco acentuadas, sendo um fator de preservação da vida aquática dos recursos hídricos desta bacia.

A velocidade não apresentou relações com a condutividade, que por sua vez, está intimamente relacionada com o TDS das águas, pois quanto maior a quantidade de sólidos totais dissolvidos na água, maior a condutividade elétrica, pelos elétrons carregados por estes sólidos.

\section{Discussões}

As relações entre seus parâmetros transmitem uma importância significativa no entendimento de corpos hídricos e como os mesmos são alterados e, em alguns casos, contaminados e poluídos, portanto, entrada de algum contaminante pode alterar todos os parâmetros e suas correlações, trazendo impactos nocivos à uma bacia hidrográfica, sobretudo bacias cársticas, onde as fragilidades de seus terrenos e água são maiores.

Analisando os parâmetros encontrados, foi notável algumas características principais, a primeira delas diz respeito à baixa turbidez das águas superficiais, que não ultrapassaram 6,24 NTU, sobretudo diante da decantação dos sedimentos químicos compostos por $\mathrm{CaCO}_{3}$ e $\mathrm{CaMg}\left(\mathrm{CO}_{3}\right)_{2}$.

Se comparar esses valores de turbidez encontrados com outras bacias hidrográficas sulmato-grossenses, vê-se algumas distorções consideráveis. Segundo Braz (2017) a turbidez alcançou 17 NTU em regiões terrígenas analisadas pelo autor (localizada no setor leste do estado), podendo, em algumas situações, alcançar 217 NTU, contudo, na mesma região do estado, Oliveira et al. (2011) encontrou valores de turbidez que alcançaram 65 NTU. Tais 
valores contrastam e mostram a diferença dos ambientes cársticos e terrígenos na identificação do índice de turbidez, sendo comprovado por autores que trabalharam com diferentes regiões cársticas no município de Bonito, ou seja, Lelis et al. (2015) e Brugnolli et al. (2019a). O primeiro encontrou índices que variaram entre 1,80 NTU a 3,00 NTU no rio Formoso e o estudo de Brugnolli et al. (2019a), encontrou uma turbidez variando entre 0,81 NTU a 7,39 NTU, no rio Mimoso.

Brugnolli et al. (2019a, p. 194) ainda afirmam que as características expressas pelo pH alcalino incorporaram elementos químicos que geraram reaçoes, "na grande maioria das vezes condutoras de eletricidade e que geram sais dissolvidos, que são excelentes decantadores, que proporcionam águas muito cristalinas". Ao comparar o pH desta bacia com outras áreas cársticas do estado, foi constatado que este indicador apresentou expressivos índices alcalinos em todas as áreas, sobretudo devido às águas ricas em $\mathrm{CaCO}_{3}$. Tanto Lelis et al. (2015) como Brugnolli et al. (2019a) trazem índices próximos ou acima de 8 de $\mathrm{pH}$ nos rios Formoso e Mimoso respectivamente.

Tais sistemas fluviais alcalinos e com grande quantidade de calcita, magnésio e dolimita, trazem consigo um ambiente condutor de eletricidade, isso ainda é corroborado por Bartmann (2015), que examinou a qualidade das águas da Bacia do Rio Miranda, na qual o córrego Formosinho é afluente. Com o intuito de reforçar esta afirmação torna-se válido destacar que nossa área de estudo é composta pelo ambiente cárstico, apresentando condutividades elevadas devido ao contato com os minerais condutores, das rochas carbonatadas.

De tal forma, a condutividade elétrica nessa pesquisa alcançou índices consideráveis, variando de $183 \mu \mathrm{S} / \mathrm{cm}$ a $213 \mu \mathrm{S} / \mathrm{cm}$, em contrapartida, trabalhos em sistemas terrígenos, como o de Oliveira et al. (2011) e Schautz (2015), a condutividade apresentou uma média de $40 \mu \mathrm{S} / \mathrm{cm}$, apontando resultados inferiores, se comparado com trabalhos que abarcaram o sistema cártisco como unidade de estudo, como as pesquisas de Lelis et al. (2015) e Brugnolli et al. (2019a). Lelis et al. (2015) retrataram em seus estudos uma condutividade com valores próximos a $400 \mu \mathrm{S} / \mathrm{cm}$, já Brugnolli et al. (2019a) apontaram valores acima de $700 \mu \mathrm{S} / \mathrm{cm}$, e diante destas análises apresentamos uma característica desses ambientes cársticos. 
Portanto, por mais que o sistema cárstico apresenta características que o enquadram em classe IV, devido a alta $\mathrm{CE}$, os demais parâmetros se mostaram determinantes para um enquadramento em classes aceitáveis segundo o CONAMA (2005). Diante das análises efetuadas ao longo deste trabalho um fator tornou-se preocupante, isto é, o pH e CE elevados, trazendo consigo o que chamamos de água "dura", ou seja, águas mais encorpadas que podem ser laxativas se consumidas.

Outro fator preocupante na área de estudo são os problemas pertinentes a qualidade das águas dos recursos hídricos de Bonito relacionadas ao processo de interação das chuvas e o manejo inadequado do uso do solo em áreas de culturas para expostação de commodities . Brugnolli et al. (2019b) destaca essa questão, trazendo consigo uma realidade recorrente ao município de Bonito, ou seja, o "barreamento" das águas, isto porque o solo exposto em determinadas épocas do ano, decorrente das monoculturas, traz um carreamento de grande quantidade de sedimentos em épocas de grande volume pluvial, deixando as águas turvas (elevação da turbidez), reduzindo o OD, oferecendo condições a uma maior acidez do $\mathrm{pH}$, elevando os níveis de TDS e CE.

Além disso, o avanço da monocultura em áreas de preservação permanente, se aproxima dos mananciais e causa, portanto, preocupações e impactos negativos, que são expostos pela comunidade científica e pela mídia. De tal forma, orienta-se promover medidas capazes de eliminar ou atenuar tais impactos, resultando em uma melhor qualidade ambiental e social, visto que muitos indivíduos dependem economicamente dos atrativos turísticos desenvolvidos nas áreas cársticas.

\section{Conclusões}

Estudar os recursos hídricos de uma área com grande importância econômica e turística, e com a particularidade de estar instalada em um ambiente cárstico, como a BHCF, foi um desafio perante aos resultados encontrados e que traduziram a proposta deste trabalho, que foi analisar a forma como os mananciais hídricos estão dispostos ao longo da bacia, compreendendo suas características, traduzidas também em função da qualidade das águas superficiais. 
A análise morfométrica mostrou detalhes importantes referentes à rede de drenagem da serra da Bodoquena. Foi constatada uma redução no volume das águas nas áreas assentadas sobre as rochas carbonatadas e bicarbonatadas do médio e baixo curso da BHCF.

Tais águas superficiais se enquadraram na classe I, que preconiza seu uso para consumo humano após tratamento simplificado, bem como a proteção das comunidades aquáticas, recreação de contato primário (natação e mergulho), irrigação de hortaliças que são consumidas cruas e de frutas que se desenvolvam rentes ao solo e que sejam ingeridas sem remoção de películas e, por fim, à proteção das comunidades aquáticas em terras indígenas (CONAMA, 2005).

As rochas carbonatadas trouxeram características únicas aos recursos hídricos, que também são expressas na qualidade das águas, tendo mais influencia em determinados parâmetros, como na condutividade elétrica, $\mathrm{pH}$, TDS e turbidez. A condutividade elétrica é elevada em todos os pontos devido à influência hidrogeológica, frente ao contato com as rochas carbonatadas e bicarbonatadas, seja pelo magnésio, calcita e dolomita. Concomitante a isso, pelo mesmo motivo, o pH mostrou-se elevado (alcalino), juntamente com os sólidos totais dissolvidos.

Inversamente, a turbidez é reduzida pelo contato com rochas calcárias, por conta dos corpos hídricos não ostentarem sólidos em suspensão em demasia, isso ocorre pela floculação e decantação dos sólidos suspensos no leito fluvial perante ao teor de cálcio que calcifica os sólidos, deixando-os mais densos e reunindo-os no leito fluvial, trazendo impressionante beleza cênica aos mananciais.

Essa deposição calcária no leito fluvial favorece o surgimento das tufas calcárias, que afloram na forma de cachoeiras, corredeiras e possuem grande beleza cênica. Essas tufas calcárias, possuem interesse científico, turístico e ambiental, entretanto, é extremamente frágil e necessita de propostas para sua conservação. Tais propostas passam necessariamente pela redução na recorrência de turvamentos das águas, pois as tufas vem sendo erodidas mais rapidamente diante de tais acontecimentos e, certamente, impactará nos atrativos turísticos da BHCF a médio e longo prazo.

Os parâmetros OD, ORP, TDS e turbidez expressaram uma boa qualidade das águas superficiais, com exceção do ponto 1 (córrego Taquaral), onde a velocidade de fluxo das 
águas, condutividade e oxigenação traduziram em uma redução de sua qualidade (classe II), contudo, ainda se mostrando com qualidade mediana devido à baixa turbidez, TDS e ORP.

Essa característica ímpar, isto é, com caráter alcalino, com pH acima de 7,00, dotada de uma assinatura geoquímica cálcica, magnésica e carbonatada, devido ao expressivo teor de cálcio, magnésio e bicarbonato dissolvido, faz com que as águas superficiais exibam alta CE e TDS. Águas com este aspecto geoquímico comumente são águas avaliadas como "duras" acarretando consequência laxativa aos organismos mais sensíveis.

Por fim, frente ao que foi apresentado neste artigo, foi constatada a necessidade em elaborar planos e manejos adequados para a dinâmica de um sistema cárstico, abarcando suas fragilidades e potencialidades que impactam diretamente nos recursos hídricos, favorecendo uma boa qualidade das águas superficiais e, consequentemente, nos setores econômicos e sociais do município de Bonito.

\section{Referências}

Aquaambiente. 2004. Tratamento Águas Potáveis. 32p. Disponível em: <http://mariorebola.com/home/wpcontent/uploads/2011/09/AquaAmbiente-Tratamento-de-\%C3\%81gua-Pot\%C3\%A1vel.pdf>. Acesso em: abr de 2016.

Araújo, S. C. de S.; Salles, P. S. B. de A.; Saito, C. H. Modelos qualitativos, baseados na dinâmica do oxigênio dissolvido, para avaliação da qualidade das águas em bacias hidrográficas. Desenvolvimento tecnológico e metodológico para medição entre usuários e comitês de bacia hidrográfica. Brasília: Departamento de Ecologia. Editora da UNB, 2004. p.9-24.

Auler, A. S.; Rubiolli, E.; Brandi, R. As grandes cavernas do Brasil. Belo Horizonte: Grupo Bambuí de Pesquisas Espeleológicas, 2001, 227p.

Bartmann, R. A. da. Variabilidade Físico-química das águas da sub-bacia do rio Miranda-MS. 2015. (Dissertação Mestrado em Geografia) - Universidade Federal de Mato Grosso do Sul, Campus de Três Lagoas. 2015.

Brasil, Conselho Nacional do Meio Ambiente - CONAMA. Resolução 357/2005, Enquadramento dos Corpos Hídricos Superficiais no Brasil. Governo Federal, Brasília. Publicada no DOU n 92, de 13 de maio de 2011, Seção $1,89 p$.

Brasil. LEI № 9.433, DE 8 DE JANEIRO DE 1997 Institui a Política Nacional de Recursos hídricos, cria o Sistema Nacional de Gerenciamento de Recursos hídricos, regulamenta o inciso XIX do art. 21 da Constituição Federal,

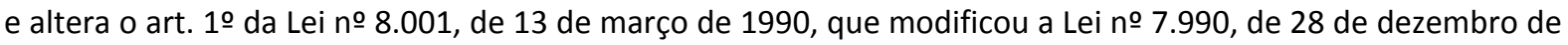
1989.

Braz, A. M. Geotecnologias aplicadas na análise das implicações entre o uso, cobertura e manejo da terra e a qualidade das águas superficiais: bacias hidrográficas dos córregos Lajeado Amarelo e Ribeirãozinho, Três Lagoas/MS.2017. (Dissertação Mestrado em Geografia) - Universidade Federal de Mato Grosso do Sul, Campus de Três Lagoas. 2017. 
Brugnolli, R. M. Zoneamento Ambiental para o Sistema Cárstico da Bacia Hidrográfica do Rio Formoso, Mato Grosso do Sul. 2020. 403p. Tese (Doutorado em Geografia) - Faculdade de Ciências Humanas, Universidade Federal da Grande Dourados, Dourados, 2020.

Brugnolli, R. M.; Berezuk, A. G.; Alves, L. B. O carste e a qualidade das águas superficiais da bacia hidrográfica do rio Sucuri, Bonito/MS. Caderno de Geografia, v. 30, n. 61, p. 499-514, 2020.

Brugnolli, R. M. Procedimentos Metodológicos para análise da Vulnerabilidade Ambiental em Bacias Hidrográficas com um Estudo de caso da Bacia Hidrográfica do Córrego Moeda, Três Lagoas/MS em 2014. 2016. (Dissertação Mestrado em Geografia) - Universidade Federal de Mato Grosso do Sul, Campus de Três Lagoas. 2016.

Brugnolli, R. M.; Berezuk, A. G. ; Pinto, A. L. . Qualidade e Enquadramento das Águas Superficiais da Bacia Hidrográfica do Rio Mimoso, Bonito/MS. CIÊNCIA GEOGRÁFICA, v. 23, p. 184-195, 2019a.

Brugnolli, R. M.; Berezuk, A. G. ; Silva, C. A. da . A morfometria da bacia hidrográfica do rio Mimoso, um sistema cárstico do Mato Grosso do Sul/ Brasil. CONFINS (PARIS), v. 40, p. 1-19, 2019b.

Brugnolli, R. M.; Pinto, A. L.; Miguel, A. E. S. Influência do Uso e Manejo Florestal dos Hortos de Eucalipto na Qualidade das Águas Superficiais da Bacia Hidrográfica do Córrego Moeda, Três Lagoas/MS. Revista de Geografia (Recife), v. 34, p. 186-200, 2017.

Carvalho Júnior, O. A; Berbet-Born, M; Martins, E. D; Guimarães, R. F; Gomes, R. A. T. Ambientes Cársticos. In: Florenzano, T. G. (Org.). Geomorfologia: Conceitos e Tecnologias Atuais. 1. ed. São Paulo: Oficina de Textos, 2008.

Christofoletti, A. Geomorfologia. São Paulo, Edgard Blücher, 2ª edição, 1980. 188p.

Companhia de Pesquisa de Recursos Minerais - CPRM. GeoBank: Mapa Geológico do Estado de Mato Grosso do Sul. 2006. Disponível em: <http://geosgb.cprm.gov.br/>. Acesso em Outubro de 2016.

Dias, J. A região cárstica de Bonito, MS: uma proposta de zoneamento geoecológico a partir de unidades da paisagem. Ensaios e ciência. Campo Grande, v. 4, n. 1, p. 09-43, abr. 2000.

ESRI 2011. ArcGIS Desktop: Release 10. Redlands, CA: Environmental Systems Research Institute.

Fritzsons, E.; Mantovani, L.E.; Chaves Neto, A.; Hindi, E.C. A influência das atividades mineradoras na alteração do $\mathrm{pH}$ e da alcalinidade em águas fluviais: o exemplo do rio Capivari, região do carste paranaense. Revista de Engenharia sanitária e ambiental, v.14, n. 16, 2009.

Horton, R.E. Erosional development of streams and their drainage basins: hydrophysical approach to quantitative morphology. Geological Society of America Bulletin. Boulder, Colorado, EUA, pp. 275-370, 1945.

Ivo, D.; Kubica, R. A instrumentação analítica utilizada na obtenção de água purificada para produção de fármacos: foco na importância da calibração, 2009. Disponível em: <http://www.labsoft.com.br/arquivos/artigos/CT-038 09.pdf>. Acesso em maio de 2016.

LELIS, M.; PINTO, A. L.; SILVA, P. V. da; PIROLI, E. L.; BRUGNOLLI, R. M.; GOMES, W. M. Qualidade das águas superficiais da bacia hidrográfica do rio Formoso, Bonito - MS. Revista Formação, v. 2, p. 279-302, 2015.

Libânio, M. Fundamentos de qualidade e tratamento de água. Campinas: Átomo, 2005.

Mantovani, L. E.; Fritzsons, E.; Wrege, M. S. Aspectos Hidrológicos e Hidrogeológicos da Bacia do Rio Fervida, Aquífero Carste, Colombo, Paraná. Revista Ra'e Ga, Curitiba, v. 37, p. 190-206, 2016.

Mato Grosso do Sul, LEI № 1.871, DE 15 DE JULHO DE 1998. Institui Incentivo Fiscal a Projetos Culturais no Estado, e dá outras providências. 
Mato Grosso do Sul. LEI N 2.223, DE 11 DE ABRIL DE 2001. Responsabiliza os proprietários e arrendatários de imóveis rural e urbano, pela poluição hídrica dos rioscênicos, e da outras providências.

Oliveira, G. H.; Pinto, A. L.; Fernandes, M. V. F.; Araujo, A. F. Balneabilidade no Baixo Sucuriú, Município de Três Lagoas/MS. Revista de Geografia, Meio Ambiente e Ensino - GEOMAE (Online), v. 2, p. 79-89, 2011.

Parise, M. Management of water resources in karst environments, and negative effects of land use changes in the Murge area (Apulia, Italy). Karst Development: Original Papers, v. 2., n. 1, p. 16-20. 2012.

Pinto, André L.; Lorenz Silva, J. L.; Ferreira, A. G.; Basso, P. M. Subsidio Geológico/Geomorfológico ao ordenamento do uso, ocupação e manejo do solo, visando à redução da perda de solo e a recuperação da qualidade das águas superficiais da Bacia do Córrego Bom Jardim, Brasilândia/MS. Relatório Parcial FUNDECT/MS. UFMS. Três Lagoas, 2009: 42p.

Schautz, L. C. A. Avaliação da qualidade da água do Rio Dourados/MS - Variáveis FísicoQuímicas. Dourados/MS. 2015. (Dissertação Mestrado em Química) - Universidade Federal da Grande Dourados. 2015.

Silva Júnior, I. R. da; Alves, L. da S. F.; Pinto Filho, J. L. de O. Água como um bem social público: os processos de privatização face ao abastecimento público em Pau dos Ferros- RN. GEOSUL (UFSC), v. 33, p. 58-82, 2018.

Silva, J. P. S. Impactos Ambientais Causados por Mineração. Revista Espaço da Sophia, n. 8, 2007.

Soares, M.; Oka-Fiori, C.; Silveira, C. T.; Kaviski, E. Avaliação do Método de Levantamento morfométrico em Bacias Hidrográficas através da Estatística Multivariada. GEOSUL (UFSC), v. 33, p. 83-97, 2018.

Souza, J. R. de; Moraes, M. E. B. de; Sonoda, S. L.; Santos, H. C. R. G. A Importância da Qualidade da Água e os seus Múltiplos Usos: Caso Rio Almada, Sul da Bahia, Brasil. Revista Eletrônica do Prodema, v.8, n.1, p. 26-45, abr. 2014, Fortaleza, Brasil, ISSN: 1982-5528

Toledo, G.L., Nicolella, G. Índice de qualidade de água em microbacia sob uso agrícola e urbano. Embrapa Meio Ambiente, Scientia Agricola, v.59, n.1, p.181-186, 2002.

Van Beynen, P. E.; Van Beyden, K. M. Human Disturbance of Karst Environments. In: Van Beynen (eds.). Karst Management. Springer, Dordrecht. pp 379-397. 2011.

Waele, J. D.; Gutiérrez, F.; Parise, M.; Plan, L. Geomorphology and natural hazards in karst areas: A review. Geomorphology, v.134, p. 1-8. 2011.

Zavattini, J. A. Dinâmica Climática no Mato Grosso do Sul. Geografia, Rio Claro, 17(2): 65-91, outubro/1992. 